\title{
Type A dissections in patients with Marfan syndrome: When less is not more
}

\author{
Jennifer J. Chung, MD, ${ }^{\mathrm{a}}$ Jonathan Gordon, BA, ${ }^{\mathrm{b}}$ and Pavan Atluri, $\mathrm{MD}^{\mathrm{a}}$
}

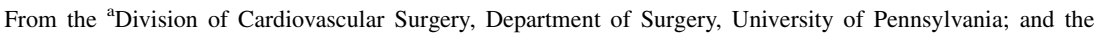
${ }^{\mathrm{b}}$ Sidney Kimmel Medical College, Thomas Jefferson University, Philadelphia, Pa. Disclosures: Authors have nothing to disclose with regard to commercial support.

Received for publication May 11, 2017; accepted for publication May 23, 2017; available ahead of print June 21, 2017.

Address for reprints: Pavan Atluri, MD, Hospital of the University of Pennsylvania, 3400 Spruce St, Silverstein 6, Philadelphia, PA 19104 (E-mail: Pavan.Atluri@uphs.upenn.edu).

J Thorac Cardiovasc Surg 2017;154:1169-70

$0022-5223 / \$ 36.00$

Copyright (c) 2017 by The American Association for Thoracic Surgery

http://dx.doi.org/10.1016/j.jtcvs.2017.05.069
}

Ideal management of patients with Marfan syndrome (MFS) and type A aortic dissection (TAAD) remains an unresolved dilemma between mitigating the potentially devastating consequences of untreated aortic disease and minimizing morbidity and mortality associated with surgical intervention. MFS, a connective tissue disorder resulting from a mutation in the fibrillin-1 gene, is associated with a number of aortic pathologies, ${ }^{1,2}$ and approximately $20 \%$ to $25 \%$ of affected individuals will have TAAD develop in their lifetimes. ${ }^{3}$ Optimal treatment of TAAD in these patients requires consideration of the unique challenges associated with MFS, including high rates of recurrent aneurysm in the distal arch as well as thoracic and thoracoabdominal aortic involvement, requiring subsequent reoperations. ${ }^{4,5}$

Acute TAAD in the general population is often treated with a minimalist approach. The life-threatening arch dissection is addressed in a limited and urgent manner, followed by subsequent elective repair of remaining distal aortic disease as needed. This strategy is suboptimal in the long term in patients with MFS, who have greater than 12-fold increased odds of requiring distal aortic reintervention than do patients without MFS. ${ }^{4}$ In this issue of the Journal, Ma and colleagues ${ }^{6}$ report on an alternative approach. Their group had previously published a consecutive series of patients with MFS and TAAD treated with an aggressive early approach combining total arch replacement and open endovascular stent placement into the descending aorta ("frozen elephant trunk" technique). ${ }^{7}$ The approach involves the use of a specially designed 4-branched arch graft in conjunction with the Cronus stent graft (MicroPort Scientific Corporation, Shanghai, China) to treat the descending aorta. ${ }^{6}$ The current study is one of the largest published cohorts of patients with MFS treated with this extensive approach, and the long-term follow-up by Ma and colleagues ${ }^{6}$ in this issue of the Journal provides much needed insight into the progression of disease and late causes of morbidity and mortality in this high risk population.

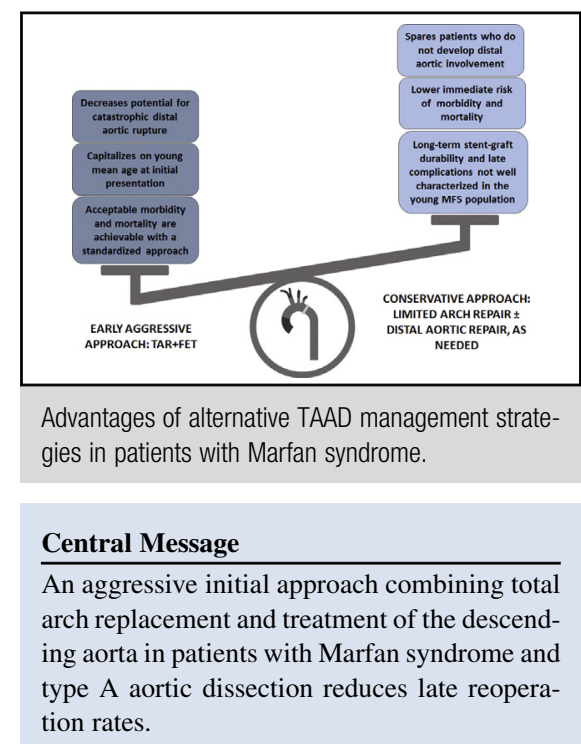

See Article page 1175 .
The study of Ma and colleagues ${ }^{6}$ challenges the "expert consensus" to avoid stent grafts in patients with MFS because of concerns regarding the chronic effects of radial forces on an intrinsically weak aorta and the durability of stent grafts. $^{8}$ Of the 106 subjects, 11 required additional interventions for thoracoabdominal aortic aneurysm $(n=8)$ or thoracic endovascular aortic repair for distal new entry $(\mathrm{n}=3)$; however, 8 years from initial operation, freedom from reoperation was $84.2 \%$, with a $74.1 \%$ survival. In contrast, Schoenhoff and coworkers ${ }^{3}$ reported a $48 \%$ reoperation rate in the distal aorta for patients with MFS who presented with acute aortic dissection and were treated primarily with proximal aortic interventions. The experience of $\mathrm{Ma}$ and colleagues ${ }^{6}$ demonstrates that superior outcomes can be achieved in patients with MFS by using their total arch replacement plus frozen elephant trunk approach. Furthermore, the protective effect of youth in this cohort (age $34.5 \pm 9.7$ years) should not be underestimated, and further supports more extensive intervention at the initial encounter. Many lessons can be gleaned from the experience of $\mathrm{Ma}$ and colleagues ${ }^{6}$ : the use of standardized conduits, emphasis on early cerebral and distal aortic reperfusion, a low threshold for concomitant aortic root repair, and close radiographic and clinical follow-up have the potential to improve long-term outcomes in high-risk patients with MFS who present with TAAD. We commend Ma and colleagues ${ }^{6}$ on their 
impressive results in this complex patient population. Further multi-institutional analysis is warranted to investigate widespread generalizability.

\section{References}

1. Isselbacher EM, Bonaca MP, Di Eusanio M, Froehlich J, Bassone E, Sechtem U, et al; International Registry of Aortic Dissection (IRAD) Investigators. Recurrent aortic dissection: observations from the International Registry of Aortic Dissection. Circulation. 2016;134:1013-24.

2. Campbell CR, Berman AE, Weintraub NL, Tang YL. Electrical stimulation to optimize cardioprotective exosomes from cardiac stem cells. Med Hypotheses. 2016;88:6-9.

3. Schoenhoff FS, Jungi S, Czerny M, Roost E, Reineke D, Matyas G, et al. Acute aortic dissection determines the fate of initially untreated aortic segments in Marfan syndrome. Circulation. 2013;127:1569-75.
4. Rylski B, Beyersdorf F, Kari FA, Schlosser J, Blanke P, Siepe M. Acute type A aortic dissection extending beyond ascending aorta: limited or extensive distal repair. J Thorac Cardiovasc Surg. 2014;148:949-54; discussion 954.

5. Uchida N, Katayama A, Kuraoka M, Katayama K, Takahashi S, Takasaki T, et al. Extended aortic repair using frozen elephant trunk technique for Marfan syndrome with acute aortic dissection. Ann Thorac Cardiovasc Surg. 2013;19: 279-82.

6. Ma W-G, Zhang W, Zhu JM, Ziganshin BA, Zhi A-H, Zheng J, et al. Long-term outcomes of frozen elephant trunk for type A aortic dissection in patients with Marfan syndrome. J Thorac Cardiovasc Surg. 2017;154:1175-89.e2.

7. Sun L, Qi R, Chang Q, Zhu J, Liu Y. Surgery for acute type a dissection using total arch replacement combined with stented elephant trunk implantation: experience with 107 patients. J Thorac Cardiovasc Surg. 2009;138:1358-62.

8. Svensson LG, Kouchoukos NT, Miller DC, Bavaria JE, Coselli JS, Curi MA, et al. Society of Thoracic Surgeons Endovascular Surgery Task Force. Expert consensus document on the treatment of descending thoracic aortic disease using endovascular stent-grafts. Ann Thorac Surg. 2008;85(1 Suppl):S1-41. 